\title{
A Gas-Cooled Reactor Surface Power System
}

\author{
Ronald J. Lipinski ${ }^{1}$, Steven A. Wright ${ }^{1}$, Roger X. Lenard ${ }^{1}$, and Gary A. Harn S ST I
}

'Sandia National Laboratories, MS-1146, P.0.Box 5800, Albuquerque, NM 87185, rjlipin@sandia.gov

\begin{abstract}
A human outpost on Mars requires plentiful power to assure survival of the astronauts. Anywhere from 50 to $500 \mathrm{~kW}$ of electric power $(\mathrm{kWe})$ will be needed, depending on the number of astronauts, level of scientific activity, and lifecycle closure desired. This paper describes a $250-\mathrm{kWe}$ power system based on a gas-cooled nuclear reactor with a recuperated closed Brayton cycle conversion system. The design draws upon the extensive data and engineering experience developed under the various high-temperature gas cooled reactor programs and under the SP-100 program. The reactor core is similar in power and size to the research reactors found on numerous university campuses. The fuel is uranium nitride clad in $\mathrm{Nb} 1 \% \mathrm{Zr}$, which has been extensively tested under the SP-100 program. The fuel rods are arranged in a hexagonal array within a $\mathrm{BeO}$ block. The $\mathrm{BeO}$ softens the spectrum, allowing better use of the fuel and stabilizing the geometry against deformation during impact or other loadings. The system has a negative temperature feedback coefficient so that the power level will automatically follow a variable load without the need for continuous adjustment of control elements. Waste heat is removed by an air-cooled heat exchanger using cold Martian air. The amount of radioactivity in the reactor at launch is very small (less than a Curie, and about equal to a truckload of uranium ore). The system will need to be engineered so that criticality cannot occur for any launch accident. This system is also adaptable for electric propulsion or life-support during transit to and from Mars.
\end{abstract}

\section{INTRODUCTION}

A human outpost on Mars requires plentiful power to assure survival of the astronauts. Copious electric power allows utilization of in-situ resources to make rocket fuel for the return trip, to replace leaked oxygen, and to resupply lost water. It also allows growing of vegetables under high-intensity spectrum-tailored lights. Solar energy is available for small jobs, but the intensity is only $40 \%$ of that at in space at earth's distance from the sun, the day-night cycle on Mars reduces the average power by $50 \%$, the normal Mars atmosphere reduces the power by another $40 \%$, the sun's motion across the sky reduces the average power even further unless tracking systems are emplaced, accumulation of normal dust reduces solar panel absorption by $0.25 \%$ per day, and dust storms can reduce solar intensity by another factor of 2 to 10 for periods of days to weeks. Electrical storage media (batteries, rechargeable fuel cells, etc.) must be available for the daily 12-hour night as well as for dust storms. All these factors conspire to make solar power a poor choice for the primary life-support system of a Mars base.

The first Mars base will need from $50 \mathrm{kWe}$ to $500 \mathrm{kWe}$, depending on how much risk, in-situ propellant production, life-cycle closure, and scientific activity is desired. A $250-\mathrm{kWe}$ solar array would need to be several football (or soccer) fields in size to yield this average power output. A fission reactor system would be the size of a mid-sized automobile, including the shield and heat-rejection system. The reactor would be about the same power as the research reactors found on numerous university campuses. Because a reactor does not develop a significant radiological inventory until it is operated, the reactor would be essentially non-radioactive at launch. The radioactivity would be about equal to a truckload of uranium ore.

There are numerous reactor approaches to choose from. Reactor technology is very well established and proven in the U.S. and the rest of the world. Reactors are not complicated structures. Most of the high technology is in choosing the correct materials, isotopically enriching the uranium, and establishing the geometry by careful design. After that, a simple motion of a few control elements causes heat to be produced without chemical reactions, and a flowing coolant removes this heat for use in making electricity. A reactor is not as complicated in operation as an 


\section{DISCLAIMER}

This report was prepared as an account of work sponsored by an agency of the United States Government. Neither the United States Government nor any agency thereof, nor any of their employees, make any warranty, express or implied, or assumes any legal liability or responsibility for the accuracy, completeness, or usefulness of any information, apparatus, product, or process disclosed, or represents that its use would not infringe privately owned rights. Reference herein to any specific commercial product, process, or service by trade name, trademark, manufacturer, or otherwise does not necessarily constitute or imply its endorsement, recommendation, or favoring by the United States Government or any agency thereof. The views and opinions of authors expressed herein do not necessarily state or reflect those of the United States Government or any agency thereof. 


\section{DISCLAIMER}

Portions of this document may be illegible electronic image products. Images are produced from the best available original document. 
mixture fraction, ignited by a spark at just the right time to push a cylinder in coordination with the other cylinders, and exhausted through valves that open and close at just the right time, all at 2000 times per minute.

The most thoroughly proven and utilized reactor system is a light water reactor (LWR). Other developed types are heavy water reactors, sodium-cooled reactors, and gas cooled reactors. Because of the need to avoid freezing of the water, and because of the desire to achieve high efficiency via high temperature, we consider the gas-cooled option here. But an adaptation of an LWR should also be considered in future studies. A major advantage of a gas-cooled reactor is that the coolant can couple directly to a high-efficiency gas turbine for electrical conversion. Nearly all of the electricity in the U.S. is produced by turbines (steam or gas) and all jet airplanes use lightweight turbines for propulsion. The technology is very well developed.

\section{SYSTEM DESCRIPTION}

The fission-based electric power system utilizes many of the technologies and insights from the SP-100 program (Mondt, 1994). The main difference is replacement of the $4.2 \%$ efficient thermoelectric conversion system used in SP-100 with a closed Brayton cycle and generator to obtain a ten-fold increase in conversion efficiency. The heat rejection system is also much more efficient since it can use the Martian atmosphere.

The primary building blocks of a complete surface power system are a reactor, a turbine/generator/compressor unit (turbomachinery) to convert the heat to electricity, an recuperative heat exchanger to increase the efficiency, a heat rejection unit, piping, and controls. Figure 1 shows the functional layout of the system. It produces $250 \mathrm{kWe}$ of net electric power (after subtracting off $33 \mathrm{kWe}$ for the cooler fan) with $43.8 \%$ efficiency. Heat is produced in the reactor and is transferred to the flowing gas. This gas pushes a turbine in the turbomachinery and loses pressure and temperature as it does so. An electrical generator is attached to the same shaft as the turbine and generates electricity

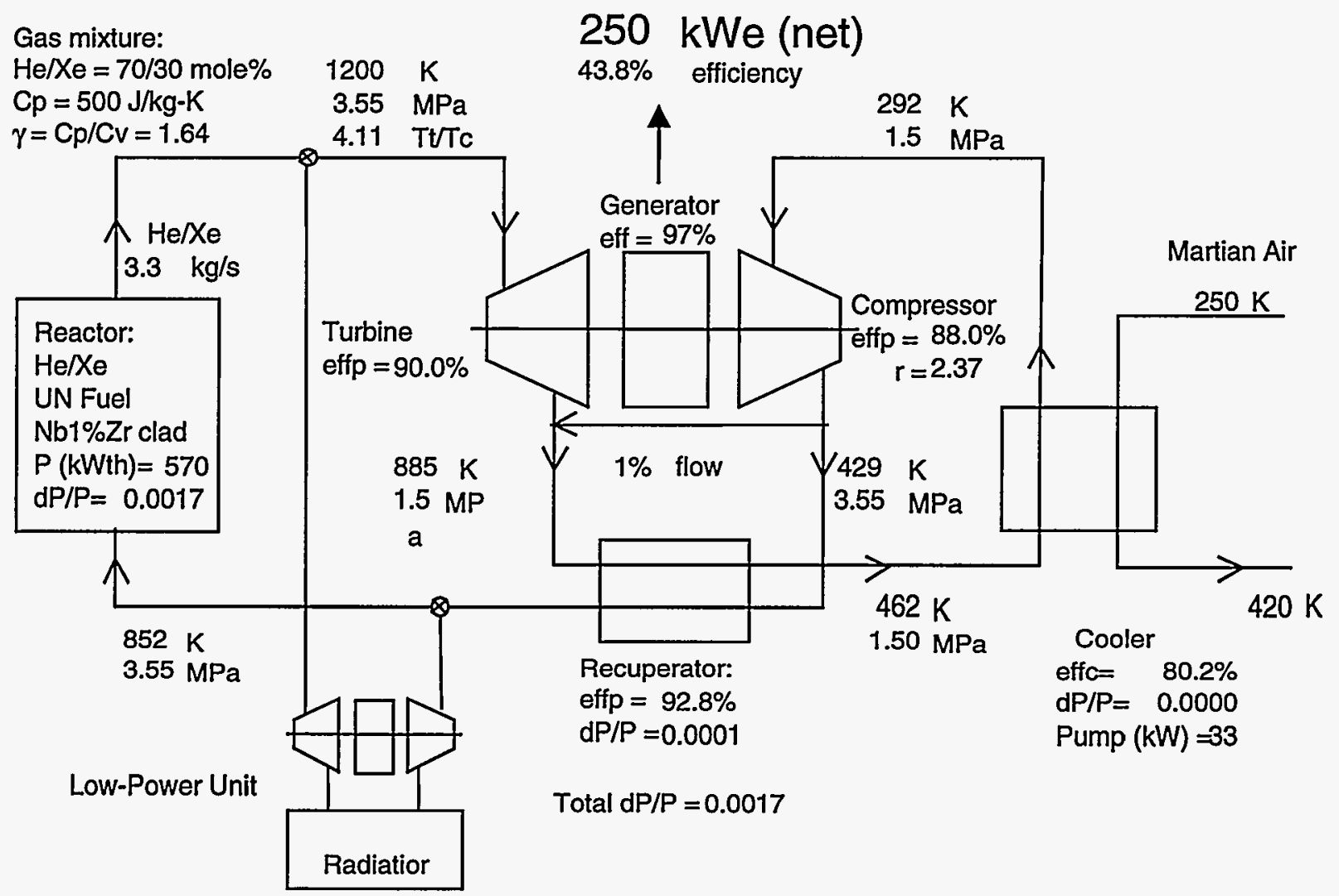

FIGURE 1. Functional diagram of the power generation system. 
as the turbine turns it. The gas then proceeds toward the heat rejection unit, but first it enters a recuperative heat exchanger where it transfers some of its heat to gas returning from the heat sink on its way back to the reactor. This reduces the amount of heat the radiator has to radiate and also reduces the amount of heat the reactor has to add to the gas for the next pass. This exchange increases the overall efficiency of the cycle. The gas then passes into the heat rejection unit (another heat exchanger) which dumps the heat to the Martian atmosphere. When the gas exits the heat rejection unit it enters the compressor in the turbomachinery unit. This compressor is attached to the same shaft as the turbine and electrical generator. So it is the turbine which supplies the power to compress the gas entering compressor. When the gas leaves the compressor, it is at higher pressure, and this is what drives it through the recuperator again, through the reactor, and through the turbine.

It is the transfer of heat from a high-temperature source (the reactor) to a low temperature sink (the heat rejection unit) that allows this process not only to continue, but to generate excess power besides. The most efficient cycle possible is a Carnot cycle. The recuperation stage in a Brayton cycle allows it to come closer to Carnot efficiency. The advantage of the recuperated Brayton cycle over a Carnot cycle is the availability of very lightweight and compact cycle components (turbines and compressors) (Van Wylen, 1994). Note that the full temperature range of the cycle (from turbine exit temperature to compressor inlet temperature) is $908 \mathrm{~K}$. This large temperature span is enabled by using a high-temperature gas-cooled reactor (rather than water-cooled) and the cold Martian air as a heat sink. The Carnot efficiency for this temperature range is $76 \%$, and the recuperated Brayton cycle is achieving only 44\%. So there is still room for improvement, if that improvement can be achieved without greatly increasing operational risk, schedule risk, development cost, or capital cost. The electrical power produced is controlled by either varying the thermal power produced by the reactor (and letting the exit temperature change accordingly) or by bleeding off some of the gas from the compressor directly back to the turbine. There also is a mini-Brayton system to provide startup power and temporary decay heat removal when the reactor is shut down; this smaller Brayton can be powered by batteries trickle-charged by a small solar panel.

A set of system equations was established for the performance of the recuperated Brayton cycle, pressure drops and temperature changes in each of the major systems, and mass of each component. The set is too large to report here, but was transferred to a 400-line spreadsheet for parameter variations. In addition, separate code runs were made for the criticality and design of the reactor and the performance of the (biological) radiation shield. Reactor calculations used TWODANT (Alcouffe, 1995) and shielding calculations used the MORSE module in SCALE (Parks, 1997). This resulted in the self-consistent and moderately optimized configuration shown in Figure 1. Figure 2 shows an artist's sketch of what the components might look like. Addressed below are the major components: the reactor, the radiation shield, the turbo/generator/compressor, the recuperator, and the heat sink.

\section{REACTOR}

The reactor is gas cooled to couple better with the Brayton system. Figure 3 shows the approximate configuration. The gas is $70 / 30$ mole- $\% \mathrm{He} / \mathrm{Xe}$; the helium increases the thermal conductivity of the mixture for better heat removal, and the xenon increases the average molecular weight to increase turbine and compressor efficiency. The fuel is uranium nitride (UN), which is the same fuel extensively tested for longevity in the SP-100 program (Mondt, 1994). The active core is $0.40 \mathrm{~m}$ in diameter and $0.50 \mathrm{~m}$ long. There is a radial reflector of beryllium metal $0.15-\mathrm{m}$

thick, and two axial reflectors of $\mathrm{BeO}$, each $0.10-\mathrm{m}$ thick. The fuel rods are held in a lattice of $\mathrm{BeO}$ with a $2.0-\mathrm{mm}$ thick flow channel around each rod for the gas coolant. The $\mathrm{BeO}$ provides a small amount of moderation. The control elements are three sliding reflectors of beryllium metal. The reactor is designed to have a strong negative thermal feedback that allows the reactor power to naturally follow variations in load without needing adjustment of the control elements. The reactor design led to explicitly derived values for the temperature of the gas and fuel, pressure drop through the reactor, and system mass.

\section{TURBOMACHINERY}

There is a very extensive industrial data base and fabrication experience for open-cycle Brayton units: they form the basis for commercial and military jet engines as well as helicopter engines. Brayton conversion systems have 


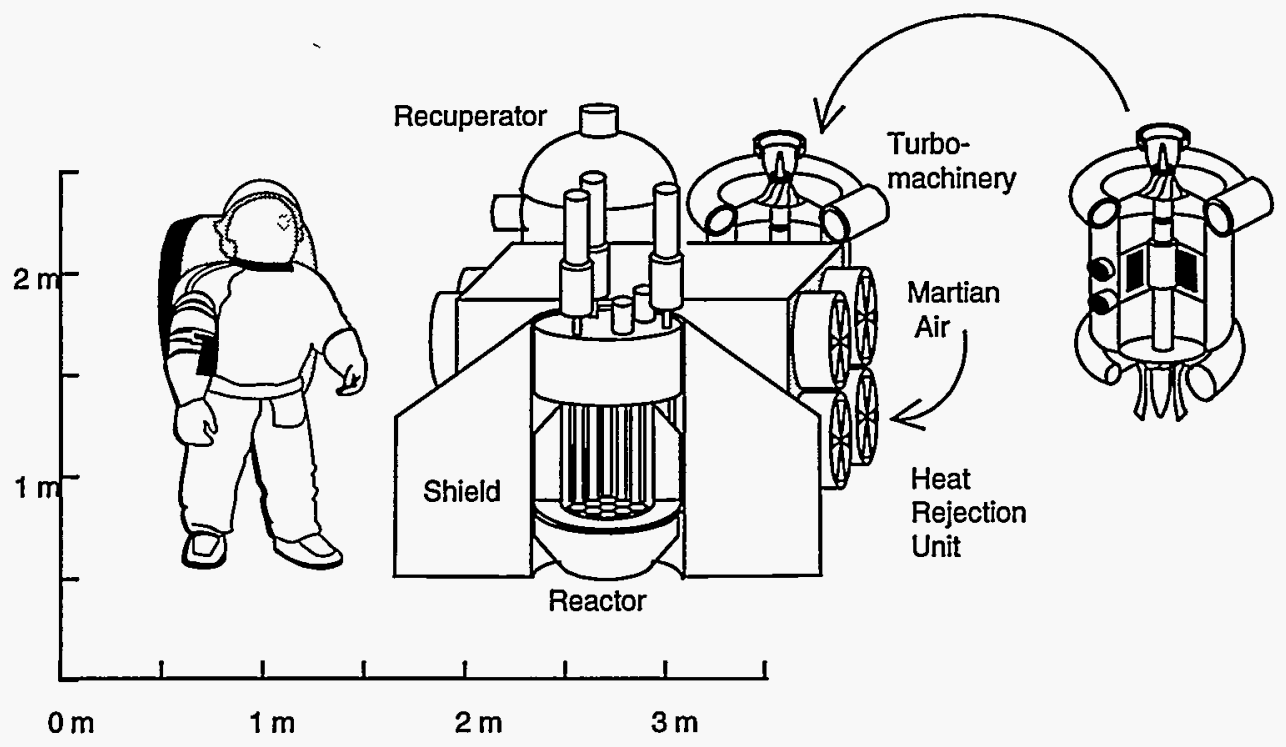

FIGURE 2. Components for the Mars base power system.

\section{Reactor Configuration}
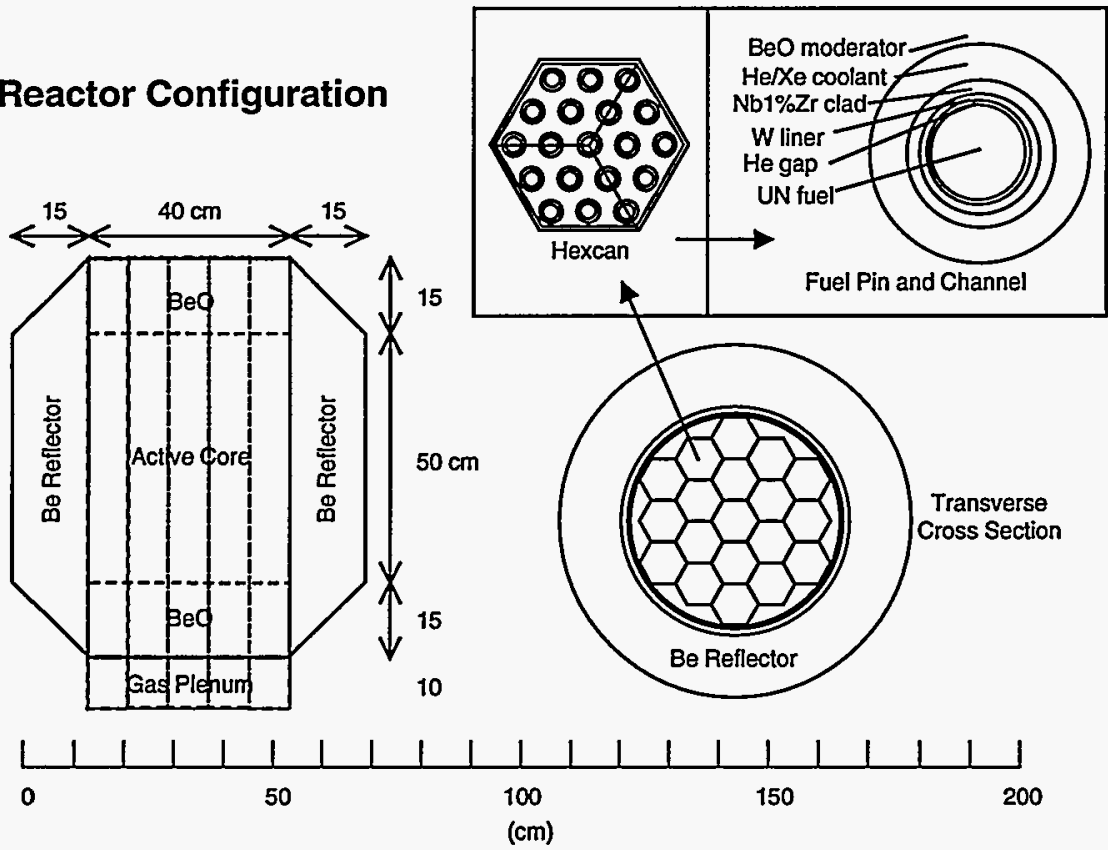

FIGURE 3. Longitudinal and transverse cross-sections of reactor.

one moving part: a single shaft connected to the turbine, the electrical generator rotor, and the compressor. In closed systems, this single shaft floats on a gas bearing bled off from the main gas flow and returned to it. With a good design, the system should last for many years without maintenance. A specific design was not developed for the turbomachinery for this system. Rather, past studies were reviewed along with presently available industrial products. The net result was a rough scaling law for the turbomachinery for mass vs. power. 


\section{RECUPERATOR}

Numerous recuperator designs are possible. This study used a tube-in-shell counterflow heat exchanger design as representative of the performance and weight of a prototypic system. The higher-pressure gas is run through the tubes, and the lower pressure through the shell. The wall thicknesses are sufficient to contain the pressures with a safety factor of at least two at operating temperature. The key to success here is to have many tubes in parallel to allow as much surface area as possible without creating a large pressure drop that would cut into the system efficiency. The recuperator is $0.85 \mathrm{~m}$ in diameter with $1.2-\mathrm{m}$ long tubes. There are about 34,000 tubes, each with a 3-mm inner diameter. This is more elaborate than traditional earth-based recuperators are, but it is very cost effective for this mission. The detailed designs led to explicitly derived heat-exchanger efficiency, pressure drops, temperature drops, and component mass.

\section{HEAT REJECTION UNIT}

The heat rejection unit is a heat exchanger cooled by Martian air with forced convection. The design is essentially the same as the recuperator (tube in shell), with the high-pressure side (tubes) flowing with the gas from the reactor and turbomachinery, and the low-pressure side (shell) flowing with Martian air. This design is not optimal, but it was a convenient reference design given the limited scope of this study. Martian air is carbon dioxide at about $0.7 \%$ atmospheric pressure $(700 \mathrm{~Pa}$ ) with a temperature that varies from $197 \mathrm{~K}$ to $263 \mathrm{~K}$ at the equator from night to day. The air is not very dense, but it is adequate, especially considering how low the average temperature is. The cooler is $1.2 \mathrm{~m}$ tall, $2.0 \mathrm{~m}$ long, and $1.1 \mathrm{~m}$ wide. It has about 42,000 tubes and uses $33 \mathrm{kWe}$ for the blower. It does not require any unfolding to deploy it, it will not be blown over by the wind or covered by dust, it is compact and

lightweight, and it is much more effective at waste-heat rejection than a system using thermal radiation. Redundant fans can be installed if there is any concern about reliability of this single moving part on the cooler.

\section{RADIATION SHIELD}

The design of the radiation shield is sensitive to the assumptions about deployment configuration. If the power system is wheeled out behind a hill or into a nearby depression or crater, it only needs a small top shield to prevent reflected radiation from the atmosphere. But if it is within a hundred meters of the base, it will need substantial shielding. In-situ resources on Mars might supply some of this shielding. Before the reactor is first operated, the radiation levels are low enough that astronauts can work near it to build a mound around it (using robotics is desired). Alternatively, the Martian atmosphere can be either condensed or frozen to build up a thick shield. (Cold carbon dioxide liquefies at $3.5 \mathrm{MPa}$ at $273 \mathrm{~K}$ and has a density of $930 \mathrm{~kg} / \mathrm{m}^{3}$.) In addition, the other system components can provide some shielding in an integrated system.

A cylinder around the reactor with a beveled top edge and a top lid was assumed. For ease and surety of deployment, it was assumed that the power system would be only $100 \mathrm{~m}$ from the base living and working quarters. In addition, a full-circle shield was used so as to allow full scientific access to all Martian areas near the base. The cylindrical portion of the shield has $7.7 \mathrm{~cm}$ of tungsten to absorb gammas and $60 \mathrm{~cm}$ of lithium hydride to slow and absorb neutrons. Credit is taken for the moderating effects of the $\mathrm{Be}$ and $\mathrm{BeO}$ reflectors on the reactor, but no credit is taken for the shielding effect of the recuperator, heat rejection unit, or turbomachinery. The shield is $1.13 \mathrm{~m}$ tall but begins to taper at the $0.70-\mathrm{m}$ mark. The sky shield is $7 \mathrm{~cm}$ of tungsten and $28 \mathrm{~cm}$ of lithium hydride (LiH) to reduce reflected radiation from the atmosphere. The combined shield reduces the dose from the reactor by about a factor of about $10^{7}$ and results in about $0.18 \mathrm{Rem} / \mathrm{yr}$ for continuous exposure at a distance of $100 \mathrm{~m}$. (This is $50 \%$ of the natural background exposure on earth.) There are two strong caveats to these numbers: 1) they are very preliminary and approximate, and 2) they assume no leakage through cracks and apertures. To effectively eliminate shine through apertures will require very careful design. Some of the shield material could be replaced by liquid carbon dioxide; this could result in a mass savings of several tonnes. 
TABLE 1. System masses.

\begin{tabular}{lr}
\hline Component & Mass (kg) \\
\hline Reactor \& controls & 834 \\
Radiation shield & 5940 \\
Turbine, generator, compressor, ducts & 862 \\
Power conditioning \& distribution & 162 \\
Recuperator & 362 \\
Heat rejection unit & 574 \\
Mini-Brayton system & 100 \\
Mechanical structure & 220 \\
Contingency (10\%) & 905 \\
Power system total mass with $\mathrm{LiH}_{\text {radiation }}$ shield & 9959 \\
Power system total mass minus $\mathrm{CO}_{2}$ radiation shield & 8000 \\
\hline
\end{tabular}

\section{SYSTEM MASSES}

The mass of each component was either calculated from the detailed design or estimated from similar components in other systems. The summary of the resulting masses is shown in Table 1. The total system weighs about $10,000 \mathrm{~kg}$, which translates to a specific mass of $40 \mathrm{~kg} / \mathrm{kWe}$ (or $25 \mathrm{~W} / \mathrm{kg}$ ). Most of this is due to the radiation shield to allow continuous human activity to within $100 \mathrm{~m}$ of the reactor.

\section{SUMMARY}

A 250-kWe surface power source for a Mars base is described. This level of power helps assure astronaut safety and mission success. It uses a recuperated closed Brayton cycle and consists of a fission reactor, turbine, electrical generator, compressor, recuperator, and heat exchanger with the Martian atmosphere. The overall thermal efficiency is $44 \%$, due partly to the low-temperature heat sink provided by the cold Martian air.

\section{ACKNOWLEDGMENTS}

The authors wish to thank Marty Sherman, Dave Bodette, and Mitch McCrory of Sandia for their for his helpful advice on heat exchangers. This activity supported by Sandia National Laboratories. Sandia is a multiprogram laboratory operated by Sandia Corporation, a Lockheed Martin Company, for the United States Department of Energy under Contract DE-AC04-94AL85000.

\section{REFERENCES}

Mondt, J. F., Truscello, V. C., and Marriott, A. T., "SP-100 Power Program," in Eleventh Symposium on Apace Nuclear Power and Propulsion, Albuquerque, NM 1995, edited by Mohamed El-Genk, CONF 940101, 1994 , pp. 143-155.

Van Wylen, G., Sonntag, R., and Borgnakke, C., Fundamentals of Classical Thermodynamics, New York, John Wiley \& Sons, 1994, pp. 367-380.

Parks, C. V., Editor, SCALE: A Modular Code System for Performing Standardized Computer Analysis for Licensing Evaluation, NUREG/CR-0200, Rev. 5, Oak Ridge National Laboratory, Oak Ridge, TN, 1997.

Alcouffe, R. E., Baker, R. S., Brinkley, F. W., Marr, D. R., ODell, R. D., and Walters, W. F., DANTSYS: A Diffusion Accelerated Neutral Particle Transport Code System, LA-12969-M, UC-705, Los Alamos National Laboratory, Los Alamos, NM, 1995. 